\title{
Experiences of women in survivorship following mastectomy in the Cape Metropole
}

\author{
NE Stecher, MA Cohen, EJ Myburgh \\ Department of Nursing, Faculty of Health Sciences, University of Stellenbosch, South Africa \\ Corresponding author: NE Stecher (stecher06@gmail.com)
}

\begin{abstract}
Background: In spite of significant improvements in the treatment of breast cancer, many women still undergo mastectomy. The effects of breast cancer surgery on the diverse population of South African women have not been well studied. Insight may be gained in how to aid recovery in survivorship by identifying the support needs of women following mastectomy. This study aimed to explore and describe the lived experiences of women in the Cape Metropole following mastectomy in survivorship.

Methods: A qualitative study guided by descriptive phenomenology and grounded in the post positivist philosophy of Husserl. Seven women from the Cape Metropole were interviewed in English following ethical approval. The semistructured interviews were thematically analysed.

Results: Three general themes emerged: Psychological impact of breast cancer diagnosis and treatment, the impact of an altered body image and concern for family and reliance on them for support, with a theme specific to stigmatisation within the Xhosa culture.

Conclusion: The need to shield family members from breast cancer diagnosis was contrasted by the need for family support. Cultural stigmata still prevail within the South African population.

Key words: body image, breast cancer, family support needs, psychological experiences and mastectomy, Xhosa culture and cancer.
\end{abstract}

S Afr J Surg 2019;57(1)

http://dx.doi.org/10.17159/2078-5151/2019/v57n1a2746

\section{Background}

Breast cancer is the most frequent non-cutaneous cancer in women in both developed and developing countries. ${ }^{1}$ Surgery remains an integral part of the treatment for breast cancer. Despite the move towards progressive breast conservation from the $1970 \mathrm{~s},{ }^{2}$ a significant number of patients will undergo mastectomy with or without axillary clearance. ${ }^{3}$ Although the term survivorship in the medical context refers to a period $\geq 5$ years after a life-threatening disease, cancer survivorship is regarded as the period following primary therapy up to cancer recurrence or death. ${ }^{4}$

Women's experiences after breast cancer diagnosis include fear of the future, recurrence of the disease, feelings of loss, concerns regarding body image and self-concept, which relate to role adjustment and family responses in survivorship. ${ }^{5}$

The research problem was based on the assumption that healthcare workers may not fully experience the impact of mastectomy on women due to their limited interaction with the patient during selective phases of their treatment and recovery.

The researcher, a professional operating room nurse, assisting with breast surgeries, identified a need and purposed to explore and describe the lived experiences of women in the Cape Metropole in survivorship following mastectomy, in order to establish what their support needs are. This is significant so that insight may be gained in how to aid their recovery in survivorship.

The research question asked 'What are the lived experiences of women residing in the Cape Metropole in South Africa, in survivorship following mastectomy?'

\section{Methods}

Ethical approval (reference S14/11/266) for this study was obtained from the Health Research Ethics Committee of Stellenbosch University. A qualitative study guided by descriptive phenomenology was undertaken based on the post-positivist philosophy of Husserl who avers that reality is a creation of the individuals involved in the research and is therefore subjective. ${ }^{6}$ The inclusion criteria was Englishspeaking women residing in the Cape Metropole who had undergone uni- or bilateral mastectomy for breast cancer regardless of adjuvant or neo adjuvant therapy or the treatment centre.

With guidance from a local breast cancer support group, semi-structured interviews were conducted in English. The 
Table 1. Participant biographic data and interview schedules

\begin{tabular}{|c|c|c|c|c|c|c|}
\hline $\begin{array}{l}\text { Participants } \\
2015\end{array}$ & Age & Race & Surgery & $\begin{array}{c}\text { Years post } \\
\text { Surgery }\end{array}$ & Interview Date & $\begin{array}{c}\text { Interview with } \\
\text { data verification }\end{array}$ \\
\hline Pilot interview & 49 & African & $\begin{array}{l}\text { Right breast wide excision, left } \\
\text { symmetry }\end{array}$ & 1 year & $\begin{array}{c}26 \text { Feb } 2015 \\
20 \text { August } 2015\end{array}$ & $\begin{array}{c}13 \text { May } 2015 \\
26 \text { August } 2015\end{array}$ \\
\hline Interview 2 & 52 & Caucasian & Left mastectomy with prosthesis & 10 years & 20 March 2015 & 15 April 2015 \\
\hline Interview 3 & 42 & Asian & Right mastectomy, no prosthesis & 8 months & $\begin{array}{l}\text { (a) } 1 \text { April } 2015 \\
\text { (b) } 18 \text { April } 2015\end{array}$ & $\begin{array}{l}18 \text { April } 2015 \\
4 \text { June } 2015\end{array}$ \\
\hline Interview 4 & 52 & Caucasian & Bilateral mastectomy with prosthesis & $1 \mathrm{yr}, 2 \mathrm{mnth}$ & 22 April 2015 & 4 June 2015 \\
\hline Interview 5 & 58 & Colored & Left mastectomy, no prosthesis & $1 \mathrm{yr}, 4 \mathrm{mnth}$ & 7 May 2015 & 4 June 2015 \\
\hline Interview 6 & 34 & African & $\begin{array}{l}\text { Right mastectomy with prosthesis, } \\
\text { left symmetry }\end{array}$ & $1 \mathrm{yr}, 2 \mathrm{mnth}$ & 20 May 2015 & 1 July 2015 \\
\hline Interview 7 & 50 & Asian & Left mastectomy, no prosthesis & $1 \mathrm{yr}, 3 \mathrm{mnth}$ & 12 June 2015 & 1 July 2015 \\
\hline
\end{tabular}

questions were based on an initial opening question "Which events occurred that led you to discover that you have breast cancer?"

This allowed the participants to freely share their experiences within a non-threatening dialogue guided by open-ended semi-structured questions and probing words. The research setting was left to the participant's choice, predominantly their homes which were neutral and private. A pilot interview provided insight into the interviewing process.

In total, seven participants were contacted via snowball/ network sampling from names provided by a local breast cancer support group of which four agreed to participate and three more were recruited via nursing colleagues and a breast surgeon. During the initial meeting, the researcher introduced her-self and the purpose of the study to the participant. The participant was free to sign an informed consent form or decline the interview. All agreed to participate. Support from a social worker/ psychologist was available if needed.

Ethically, participant autonomy, anonymity and confidentiality were ensured. Labelling the interview numerically protected each participant's privacy.

Data collection occurred from 26 February-26 August 2015 at a venue of the participant's choice via semi-structured audio-recorded interviews in English, lasting between 30-60 minutes. Field notes were kept. Participant 1 was re- interviewed in order to gain a further understanding of cultural challenges.

Participant 3's sister, present at verification shared some of her experiences in relation to coping.

Transcribed interviews were thematically analysed. This included familiarization and data immersion, inducing themes, coding, elaboration and interpretation and checking. ${ }^{7}$ The themes were presented as findings.

The trustworthiness of the study was guided by credibility, transferability, conformability and dependability. ${ }^{8}$ The credibility of the study was ensured by the authenticity of data, field notes and the verification of data by participants and the study supervisor. Transferability of data was ensured as rich data was recorded and transcribed verbatim, thematically analysed and interpreted. An audit trail of the research process ensured conformability. The research was dependable as the interviews were transcribed verbatim and is stored for 5 years.

The researcher set aside what was known to her regarding the phenomenon in order to hear the voice of the participant.

\section{Results}

All participants freely described their experiences. Three themes emerged with one theme specific to the two Xhosaspeaking participants.

\section{Theme 1: Psychological impact of breast cancer diagnosis and treatment}

Participants shared their experiences when confronted with the reality of breast cancer diagnosis. In the face of emotional distress and shock, coping mechanisms were sought for the sake of their families.

Coping mechanisms came to the fore such as acceptance.

A participant expressed her motivation for maintaining a positive attitude. 'and you sit in doctor's room... and life is just going by... that affected me quite badly.... where your life changes just within that one day... I saw somebody walk past with a cool drink and a packet of chips and I just thought you're walking here with a packet of chips and a cool drink like nothing is happening.... I was that person a few days ago... '(P7).

There was urgency for the cancer: 'to be taken away from me'(P3).

'...because I accepted it immediately...once I was finished crying, that moment the doctor said, I accepted it and I didn't look back, I didn't feel, oh, it's a breast and it's a part of me...for me the sooner you accept it then the easier ...' '(P3).

'...to me it was important that I coped well in order that my family coped well, ... if I had fallen apart, then I think everything else falls apart'(P4). 
Some participants coped by avoiding information.

Breast cancer support groups, were met with conflicting attitudes.

Chemotherapy treatment sessions provided a positive support experience.

Theme 2: The impact of an altered body image

An altered body appearance due to surgery and cancer related treatment was distressing.

Concerned about 'looking unbalanced' in front of her students, one participant opted for a bilateral mastectomy.

Hair loss was experienced individually. Some in a negative light or;

as a neutral part of the cancer journey or;

in a positive light. '...from time to time at certain stages... I know enough to just get myself by and to deal with the next stage, so ja I chose not to be too informed... and often you get people who come visit you and they want to overload you with too much information and I at some point just shut off' (P7).

'...um, you know and she's encouraged me on two occasions to join them and I actually chose not to, because they talk about it over and over again... I'd rather be in a positive space with positive people from time to time than rehashing ... all those dark experiences'(P7).

'It's like a family thing [chemo] ...because you meet everybody, same time, if you go today, three weeks later you get that same people and you keep in touch... we make friends like that'(P3).

\section{Theme 3: Concern for family members and the reliance on them for support.}

Participants wanted to protect their family from the trauma associated with their diagnosis and yet needed their family's support.

Participants felt that family needs overshadowed their own needs.

A mother of a two-year-old son attempted to maintain the bond with her son.

Emotional conflict was experienced when participants experienced a role change of carer to the one in need of care. This was due to the effects of surgery and cancer related treatment. One participant experienced a sense of guilt and helplessness toward her 16-year-old daughter.

A participant felt she had neglected her household.
'But as the time goes I think now, it started sinking in, you know... I couldn't look at my scar. I don't know why ... meanwhile people who were seeing me, they saying it's beautiful... Ah, its looking good, but I didn't feel like, I don 't know' (P1).

'... my biggest thing is that because I work with people all the time, you don't want (sigh) anything about the way you look to be a barrier between you and engaging with them'(P4).

'almost becoming uglier by the day... you know you appear to be an alien'(P7).

' I went to the mirror to look at my hair... I noticed, I don't have eyelashes... Nothing at all, under arms, nothing, it was clean, I say ok, I mustn 't panic...'I went to buy my wiggy ... the eyebrow pencils ... then I just draw, nobody even noticed that. Nobody knows that I didn't have the hair all this time I was like visiting them with wigs'(P6).

'The boys...they loved me with my bald head'(P5).
'... I didn't want him to know yet, I wanted to sort all these things out for myself'(P5).

'... I need to sit them down (her sisters) and I need to just explain to them the situation that I'm in and there's nothing to panic about. I've got breast cancer, I'm having the mastectomy done, I will still be alive ... it was a very sad moment, but I had to be the stronger of the five you know, I had to tell them, each one nicely'(P5).

'I step by step prepared them' (her two daughters) (P7).

'We had lots of mommy- time. I'd explain to him what happened that um that mommy's breast was sick'(P2).

'Oh, that was terrible because especially with the chemotherapy, I was just useless. I sort of felt guilty because I couldn't do anything for my daughter. ... I neglected her... Not that I wanted to because I really couldn 't...help myself. I was tired all the time'(P1).

'I've got a lady that comes in and help me... because of the cut I can't like sweep, mop and stuff like that. Only now recently I'm starting to do that ...' (P3). 
Participants expressed their need for support from family and friends.

Due to the stress experienced by the families of breast cancer sufferers, family and information needs came to the fore.

One participant appreciated the advice, based on experience, received from her neighbour.

Theme 4: Stigmatization within the Xhosa culture

The two Xhosa-speaking participants expressed the challenges faced within their culture as a result of breast cancer.

Stigmatization was experienced as a result of a perception that cancer is incurable and contagious.

A lack of understanding of breast surgery and prosthetic reconstruction came to the fore. A participant, who had prosthetic breast reconstruction, shared how other women responded to her.
'People to support me, especially my family, I just needed them next to me'(P6) and 'It brought the family closer um...because I think that's the most important thing, just having support around you'(P3).

'Fortunately there was a friend of mine, who was so supportive to me, we went there together... I really needed support, and I was so grateful that my friend was there' (P1).

'I think a family in this situation actually feels helpless, they don't know how to assist you.... I think it's quite important from someone who has had a mastectomy for you to be able to actually say to your family ... you're not sounding selfish' (P2).

'...because I think if it wasn't for her, then we wouldn't have been so prepared...' (Sister of $\mathrm{P} 3)$.

'...I think because, they 've got that thing of saying there is no cure'. A missing breast after mastectomy resulted in a sense of shame: '...again people they don't want to remove ... because they want to go to the grave fully, not with a part missing ....'(P1)

'....she doesn't want to play with their grandchildren, because she's like afraid that she's going to infect them' (P6).

'...you say to us you don't have a breast what we are seeing that there is a breast... why did you have to lie to us... They don't even understand what is that'(P6).

\section{Discussion}

\section{The psychological impact of breast cancer diagnosis and treatment}

The women in this study experienced emotional and psychological stress after breast cancer diagnosis and needed support in the post-treatment period.

Researchers have confirmed that women diagnosed with breast cancer experienced fear of cancer spreading, loss of control, lack of energy, feelings of sadness, depression and faced an uncertain future. ${ }^{9}$ Towsley, Beck and Watkins found that women sought to gain a sense of control over the disease and its threat to life $^{10}$ by creating a new status quo and developing coping strategies. ${ }^{11}$

In addition, Almeida et al. ${ }^{12}$ stated that acceptance was a significant point where women began to face the facts, possibilities and limitations of breast cancer.

It appeared that the participants of this study mostly found support from family and friends. As a result of physical weakness and fatigue due to cancer related treatments they were less likely to attend breast cancer support groups. However, some experienced support from other women attending the same treatment centres.

\section{The impact of an altered body image}

The participants in this study expressed their need to appear normal in society after breast cancer surgery and treatment.
A study revealed that breasts, seen as a symbol of beauty, sensuality and femininity in society played a role in selfimage and value, thus women following mastectomy experienced shame ${ }^{12}$. Arroyo and Lopez found that women, post mastectomy, experienced an 'attack' on their body image. They felt less attractive to their partners, which resulted in a low self-esteem and a sense of loss of their value as a woman. ${ }^{13}$ In addition, they felt that hair loss exposed their disease to society. ${ }^{12}$ In this study, however, while some participants found hair loss devastating, others accepted it. While some preferred a wig, others preferred a headscarf.

\section{Concern for family members and reliance on them for support}

A dichotomy emerged as the participants, carers of their families, were faced with their need for care. As supported in the findings by Almeida et al., the participants in this study experienced emotional conflict since there was a role change from caring to being cared for as they became more dependent on their family while they were in treatment. ${ }^{12}$ Researchers also showed that support needs were predominantly seen in physical elements of daily living, health care information and psychological needs. ${ }^{14}$

Families were found to be the main support structures during the participant's oncological treatment. ${ }^{12}$ Due to this burden, it was noted that the emotional impact on the family was almost as high as that of the patient. ${ }^{9}$ The findings of this study revealed that the families of women following 
mastectomy had information and support needs. It was also noted that in the absence of family some participants' friends adopted supportive roles.

\section{Stigmatisation within the Xhosa culture}

The two Xhosa participants experienced social stigmatization due to cultural misperceptions. There seemed to be perceptions of 'no cure'. Mutebi and Edge noted that a lack of understanding of the disease process, its unpredictability and complex treatments led to uncertainty. ${ }^{10}$ Breast cancer was seen as a curse and a killer disease, the "stigma of death'. ${ }^{12}$ Researchers also noted that patients felt socially isolated since breast cancer is not talked about in the Xhosa community. ${ }^{15}$ As a result of the study findings it became clear that in order to increase an understanding of breast cancer and treatment, Xhosa women needed support and education to be communicated in their mother tongue.

\section{Conclusion and Recommendations}

Breast cancer diagnosis and treatment significantly impacted the participants during survivorship.

This study highlighted some of the challenges women experienced following mastectomy, which may contribute to meaningful holistic nursing care, recovery and adaptation of these patients and their families.

The family's need for support became evident since they took on the role of primary care giver for their loved one following mastectomy.

Health care providers should be more aware of individual patient and family needs in order to facilitate recovery. Moreover, support in survivorship should be offered in the mother tongue of the patient.

Due to the recruiting method and the nature of qualitative research, the study is limited by a small sample size. Contrasted to the vast nature of cancer survivorship, cancer remains a very personal disease and valuable insight could be gained from individual interaction with women.

Qualitative research is less often presented to the scientific community and is often criticised for difficulty in quantifying outcomes and perceived bias. The large volume of raw data and the time-consuming analysis often results in limited participant numbers. It is also more difficult to demonstrate and maintain rigor, but it provides valuable data on the true human experience in an unrestricted environment, which might be more compelling than quantitative data from a controlled and limited environment. ${ }^{16}$

Further research into the challenges experienced within the Xhosa culture may bring insight into the information needs of Xhosa patients to enhance their understanding of the treatment.

In addition further research should be focused on the information and the support needs of the family.

\section{REFERENCES}

1. Jemal A, Bray F, Center MM, Ferlay J, Ward E, Forman D. Global Cancer Statistics. CA Cancer J Clin. March/April 2011[accessed 4 Apr 2014];61(2): 69-90. Available: http:// dx.doi.org/10.3322/caac.20107
2. Veronisi U, Salvadori B, Luini A, Greco M, Saccozzi R, del Vecchio $M$, et al. Breast conservation is a safe method in patients with small cancer of the breast. Long-term results of three randomized trials on 1973 patients, Eur. J. Cancer Part A. Sep1995;31A(10):1574-9. Available from: http://dx.doi. org/10.1016/0959-8049(95)00271-J

3. Elder EE, Branberg Y, Björklund T, Rylander R, Lagergren $\mathrm{J}$, Jurell $\mathrm{G}$, et al. Quality of life and patient satisfaction in breast reconstruction: a prospective study. J Breast. June 2005 [accessed 13 Mar 2014]:14(3):201-8. Available from: http:// dx.doi.org/10.1016/j.breast.2004.10.008

4. Rowland JH. Survivorhip Research: Past, Present and Future. In: Cancer Survivorship.Today and Tomorrow, ed. Patricia, A. Ganz. New York: Springer, 2007; p. 28-42.doi:10.1007/978-0387-68265-4

5. Knobf MT. Clinical Update: Psychosocial responses in breast cancer survivors. Semin Oncol Nurs. Aug 2011 [accessed 11Jun 2014];27(3):e1-e14. Available from: http://dx.doi.org/10.1016/j. sonen.2011.05.001

6. Nieuwenhuis J. Introducing qualitative research. In: First steps in research. Maree K (ed). Creswell JW, Ebersöhn L, Eloff I, Ferreira R, Evankova NV, Jansen JD. et al. Pretoria: Van Schaik, 2011; p. 65.

7. Terre Blanche M, Durrheim K, Kelly K. First steps in qualitative data analysis. In: Terre Blanche M, Durrheim K, Painter D. Research in Practice. Applied methods for the social sciences. Cape Town. University Cape Town Press, 2012; p. 322.

8. Lincoln YS, Guba EG. Naturalistic inquiry. Beverly Hills, CA: Sage, 1985; p. 316.

9. Schmid-Büchi S, Halfes RJG, Dassen T, van den Borne B. Psychosocial problems and needs of post-treatment patients with breast cancer and their relatives. Eur J of Oncol Nurs. Jul 2011 [accessed 22 Jul 2014];15(3):260-6. Available from: http:// dx.doi.org/10.1016/j.ejon.2009.11.001

10. Mutebi M, Edge J. Stigma, survivorship and solutions: Addressing the challenges of living with breast cancer in low-resource areas. SAMJ. May 2014[accessed 2 Mar 2016];104(5):383. Available from: http://dx.doi.org/10.7196/ SAMJ.8253

11. Towsley GL, Beck SL, Watkins JF. 2007. "Learning to live with it." Coping with the transition to cancer survivorship in older adults. J Aging Stud. 21 Apr 2007 [accessed Aug 2015];(2):93106. Available from: http://dx.doi.org/j.jaging.2006.08.003

12. Almeida TG, Comasetto I, Alves K de M C, dos Santos AAP, De Oliveira e Silva JM, Trezza MCSF. Experience of young women with breast cancer and mastectomized. Esc Anna Nery. Sep 2015 [accessed 3 Jun 2017];19(3):432-8. Available from: http://dx.doi.org/10.5935/1414-8145.2015005

13. Arroyo JMG, Lopez MLD. Psychological Problems Derived from Mastectomy: A qualitative Study. Int J Surg Oncol. Mar 2011 [accessed 3 Jun 2017];1-8. Available from: http://dx.doi. org/10.1155/2011/132461 2017

14. Schmid-Büchi S, Halfens RJG, Muller M, Dassen T, van den Borne B. Factors associated with supportive care needs of patients under treatment for breast cancer. Eur J of Oncol Nurs. Feb 2013 [accessed 4 Oct 2014];17(1):22-9. Available from : http://ac.els-cdn.com.ez.sun.ac.za/S1462388912000245/1-s2.0S1462388912000245-main.pdf

15. Lourens M. An Exploration of Xhosa Speaking Patients' Understanding of Cancer Treatment and Its Influence on Their Treatment Experience. J Psychosoc Oncol. Oct 2012 [accessed 4 Sep 2015]; 31(1):103-21. Available from: http://dx.doi.org/10.1 080/07347332.2012.741091

16. Anderson C. Presenting and Evaluating Qualitative Research. Am J Pharm Educ. Sep 2010 [accessed16 May 2018];74(8):141. Available from: https://www-ncbi-nlm-nih gov.ez.sun.ac.za/ pmc/articles/PMC2987281/pdf/ajpe141.pdf 